\section{ENGAGING ON ALL PLATFORMS}

Software of Excellence (SoE) invite all members of the dental team to view their latest online communication, SOE-zine, available now at www. soezine.co.uk/issue2/.

This regular publication is not limited to EXACT users; it can be accessed by all practices, bringing news, views and technique tips direct to the inbox of the UK's dental profession.

The first two issues covered news topics such as the impact of postage increases, how to prepare for the changes in NHS customer charges, and the charity work of SoE's 'Angels of Excellence'. Customer testimonials give readers a true flavour of exactly how EXACT and THRIVE are helping to improve practice efficiency and in issue 1 James Goolnik provided his thoughts on how practices can survive the recession.

SoE's vision is to engage with the profession through as many different platforms as possible. SOE-zine is a light, news format publication that readers can dip in and out of and one designed to appeal to all members of the team.

If you don't currently receive a copy of SOE-zine but would like to in the future, please email editor@ soezine.co.uk.

\section{A FINE BODY OF BUSINESS TOOLS}

Business of Dentistry, or BoD, is a business-focused service designed specifically to support the dental industry. This new online service features all the business support tools needed to grow a dental practice.

BoD offers a comprehensive package of products and services covering a wide range of business issues to help dental practices improve their business skills, increase their profits and run their business in a more efficient way.

CompliancePlus is a user-friendly, online self-assessment tool that helps dental practices meet the challenges of compliance head-on in a non-intrusive way. Once set-up and running, this service becomes a dynamic practice management tool, helping practices to demonstrate compliance as well as manage the business more effectively.

BoD offers human resources guidance and support in partnership with Peninsular; an exclusive, competitively priced offering to meet the specific personnel, employment law and health and safety needs of dental practices. For a dental practice looking to revamp their employment documentation, requiring an absence and holiday management system or simply needing advice, hronline can help.

BoD also provides dental practice insurance, discounted CRB checks, a patient-facing magazine called Smile!, workshops, events and seminars, a BlacketYellow online shop (an experienced creative design and marketing agency) and more to customers.

To benefit from BoD's exclusive offers and discounts, visit www. bodhub.co.uk.

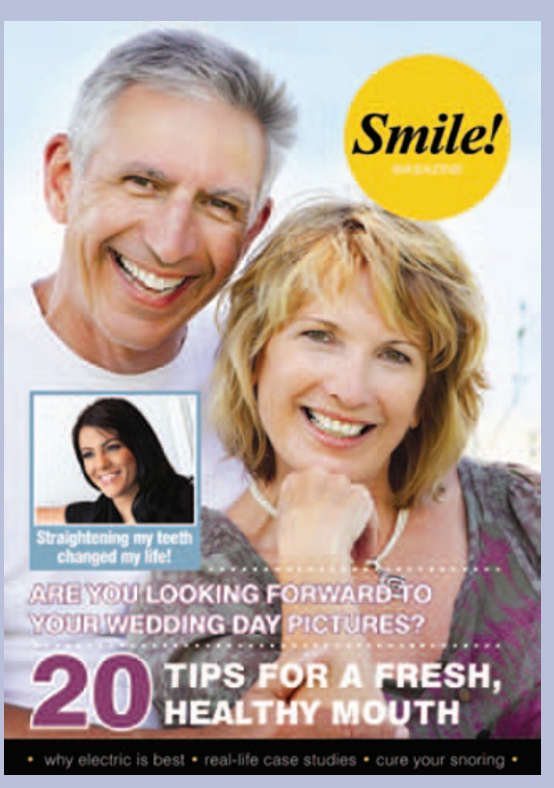

\title{
MANCHESTER 2012: EXHIBITION EYE-CATCHERS
}

More than 5,000 people attended the three-day British Dental Conference and Exhibition at the Manchester Central Convention Complex in April this year. Recently launched BKH Healthcare continued to generate curiosity and excitement, talking to clinicians looking for a partner for their business, or team members interested in seeing what benefits were available. Visitors to the accountants 4 dentists stand gained professional advice on areas ranging from basic bookkeeping to accounts preparation, tax compliance and securing finance. In addition to a warm welcome on their stand, the UCL Eastman Dental Institute provided clinical presentations in the new demonstration theatre, encouraging delegates to witness their hands-on approach to postgraduate training. Deborah Lyle of Water Pik gave an enlightening lecture on key areas of concern when maintaining proper oral hygiene with the presence of implants, providing evidence that Water Flosser devices offer significant improvements in plaque removal and gingival health. The Dental Directory had one of the most prominent stands in the exhibition, displaying a small part of its enormous range of equipment, materials and sundries. Delegates visiting the Nuview stand experienced first hand the exceptional image quality and ergonomic efficiency that the Carl Zeiss OPMI Pico dental microscope provides. The Carestream Dental stand offered their impressive collection of sophisticated, userfriendly systems to smooth dayto-day workflow and assist both CQC and HTM 01-05 compliance. Educational provider Smile-on introduced delegates to their new 'Library of Products', offering the opportunity for all members of the dental team to develop their knowledge in areas of specific interest to them. Independent Financial Adviser money4dentists fielded an experienced team of experts to give advice on issues such as pensions, savings, investments and tax. 